\title{
The regional heterogeneity of household recycling: a spatial-econometric analysis of Swedish plastic packing waste
}

\author{
Olle Hage $^{1}$ - Krister Sandberg ${ }^{2}$ - Patrik Söderholm ${ }^{1}$. \\ Christer Berglund ${ }^{3}$
}

Received: 31 May 2017 / Accepted: 28 December 2017 / Published online: 17 January 2018 C The Author(s) 2018. This article is an open access publication

\begin{abstract}
Environmental policy is often formulated at the national level, but the primary responsibilities for policy implementation, monitoring and compliance are often assigned to local actors (e.g., municipalities). This paper investigates the regional heterogeneity of household plastic waste collection among Swedish municipalities, and how collection rates have been influenced by local waste management policies, geographical conditions and socio-economic characteristics. This is achieved by employing spatial econometric methods and cross-sectional data for 282 Swedish municipalities. The results confirm the presence of spatial correlation. Furthermore, municipalities that employ weight-based waste management fees generally experience higher collection rates. The presence of curbside recycling and a high intensity of recycling drop-off stations, i.e., policy measures that help improve the infrastructural conditions for household recycling, also help explain why some municipalities perform better than others. However, the correlations between packaging waste collection and a number of important regional cost variables, such as the distance to the recycling industry, urbanization rate and population density, turn out both statistically and economically insignificant. An important explanation for this could be that the Swedish producer responsibility scheme has offered regionally differentiated (and fixed) monetary compensations to local collection entrepreneurs, and these have typically been higher in high-cost regions. This implies that plastic packaging waste collection in Sweden has been performed in a spatially cost-ineffective manner.
\end{abstract}

$凶$ Patrik Söderholm

patrik.soderholm@1tu.se

1 Economics Unit, Luleå University of Technology, 97187 Luleå, Sweden

2 Transport Analysis, Torsgatan 30, 11321 Stockholm, Sweden

3 Vattenfall Distribution AB, 97177 Luleå, Sweden 
Keywords Household recycling · Regional heterogeneity · Plastic packaging waste Waste management $\cdot$ Cost effectiveness $\cdot$ Spatial econometrics

JEL Classification $\mathrm{C} 21 \cdot \mathrm{Q} 58 \cdot \mathrm{R} 11$

\section{Introduction}

The European Union (EU) promotes a transition to a circular economy in which the value of products, materials and resources are maintained as long as possible (European Commission 2015). The circular economy involves a number of activities beyond promoting recycling of waste, such as waste prevention and re-use, material efficiency as well as sharing of products and resources (e.g., with the help of digital platforms) (see also European 2016). Nevertheless, recycling is likely to play a key role also in the future. There is potential for higher recycling rates, not the least for some materials such as plastics. Previous research has also displayed important complementary effects in that policies aimed at facilitating recycling tend to have indirect positive effects also on waste reduction (D'Amato et al. 2016a, b).

A key challenge for overall recycling policy (goals etc.), though, is that it is often formulated at the national level. However, the primary responsibility for implementation, monitoring and compliance is typically assigned to local actors. These include local authorities, private entrepreneurs, and individual households. This implies that the effectiveness of recycling policy will be influenced by a complex network of actors, the organization of their respective activities, and the incentives that they face. This paper addresses differences in household recycling outcomes across different municipal jurisdictions in Sweden, and how these outcomes in turn can be linked to differences in geographical and demographic conditions as well as to heterogeneity in waste management policies.

Previous research on the determinants of recycling outcomes (e.g., recovery rates) has often relied on case studies of one or more municipalities (e.g., Duggal et al. 1991; Sterner and Bartelings 1999; Thomas 2001; Li 2003; Tonglet et al. 2004; Lyas et al. 2005; Dahlén et al. 2007). Other research has instead focused on inter-country differences in recovery rates (e.g., Berglund and Söderholm 2003; Van Beukering and Bouman 2001). These two types of studies, though, will not fully address the importance of context-specific cost elements and local policy measures. Studies that make use of regional data, e.g., at the municipality level, include Callan and Thomas (1997), Kinnaman and Fullerton (2000), Dijkgraaf and Gradus (2004), Hage and Söderholm (2008), Abrate and Ferraris (2010), Abbott et al. (2011), Sidique et al. (2010), D'Amato et al. (2016a), and Gaeta et al. (2017). ${ }^{1}$ The low level of geographical aggregation in this latter research permits analyses of the impacts of local policies, geography, demography and various socio-economic factors. For instance, the results reported in Abbott et al. (2011) using UK data display the importance of curbside recycling and the fre-

\footnotetext{
1 Regional data have also been used to address other issues related to waste management and resource efficiency. One example is Mazzanti et al. (2009) that examine the relationship between economic growth and landfilling trends employing provincial panel data for Italy. See also Nakano and Managi (2012) who measure efficiencies incorporating waste generation using Japanese prefecture level data.
} 
quency of residual waste collection for recycling performance. In this paper we add to the above literature on regional heterogeneity in recycling outcomes, highlighting the role of both policy and various socio-economic determinants (see further below).

The purpose of the paper is to analyze the determinants of household plastic waste collection in Swedish municipalities, including the role of local waste management policy, geographical and socio-economic conditions and environmental preferences. This is achieved by using cross-sectional data for 282 Swedish municipalities and spatial econometric methods.

The Swedish producer responsibility ordinance for packaging waste was introduced in 1994. It outlines national recycling goals, such as that at least 30 percent of the plastic packaging waste should be recycled, hence used as inputs in new plastic products. The ordinance also states that the producers have the physical and the economic responsibility for the packaging waste, i.e., they are obliged to provide suitable systems for the collection and the recycling of packaging waste. In order to comply with the producer responsibility the producers have established material companies, i.e., one of these administering the plastic packaging waste collection. The producers must also consult with the municipalities.

Municipalities in Sweden have been legally obliged to take a key role in informing households about the collection systems as well as in supervising the collection schemes. Households have been obliged to clean and sort out packaging waste from other waste, and (in the absence of curbside recycling) transport used packaging materials to assigned drop-off stations. The policies aimed at encouraging households' recycling efforts, including waste handling fees, the provision of needed infrastructure etc., are designed and implemented at the municipal level. Finally, the material companies have engaged different collection entrepreneurs that operate in municipalities; these put out and empty the containers at the stations, and transport the plastic waste to recyclers. These operations have to 90 percent been funded through fees paid by the packaging producers (Hage 2007). This thus implies that recycling initiatives and outcomes have not been uniform across the country.

Our empirical focus on plastic packaging waste from Swedish households is in part motivated by the fact that - although the aggregate national target has been exceeded in recent years - there is potential for improved household recycling in the case of plastic packaging waste (Dahlén et al. 2013). Figure 1 illustrates the regional heterogeneity by displaying the amounts in $\mathrm{kg}$ of household plastic packaging waste per resident that were collected in 282 Swedish municipalities in 2005, ranked from the lowest (i.e., $0.04 \mathrm{~kg}$ per resident) to the highest (5.71 kg per resident).

This heterogeneity across municipalities forms the basis of our empirical investigation, and it permits us to make two overall contributions to existing research in the field. First, we devote particular attention to the effectiveness and the spatial cost-effectiveness of the Swedish policy design. Waste management policies in Sweden have had a strong focus on facilitating households' recycling activities, not least through increased reliance on so-called property-close waste collection (e.g., SEPA 2005). This includes, for instance, easier access to drop-off stations and containers as well as a more intense use of curbside recycling. In addition, quite a few municipalities have implemented weight-based (rather than volume-based) waste handling fees, and thereby an explicit economic incentive for households to undertake waste sorting 
Fig. 1 Household Plastic Packaging Waste Collection across Swedish Municipalities, 2005 (kg/resident) Source: Staaf (2006)

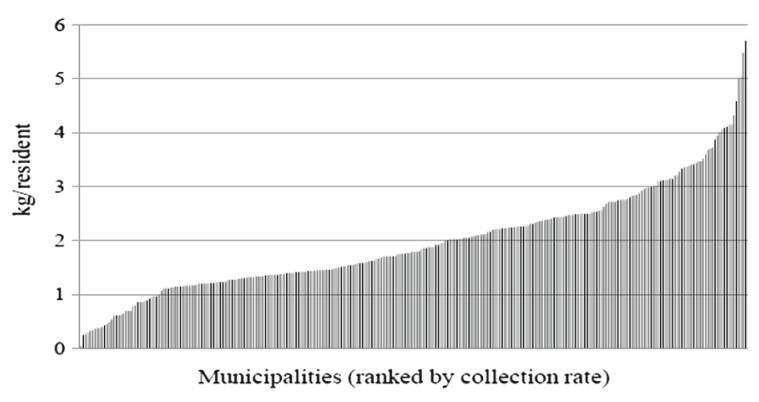

activities. Unlike most previous studies we clearly distinguish between different forms of pricing programs while at the same time controlling for the presence of curbside recycling and the density of drop-off stations. This is important if we want to provide reliable policy recommendations, especially because there usually is a close correlation between the presence of unit-based pricing and curbside recycling, respectively (Kinnaman 2006).

Furthermore, the analysis can indicate to what extent inter-municipal differences in collection rates are due to important cost differences across regions. It is reasonable to assume that both the private and the environmental costs for different waste management schemes differ across municipalities. For instance, the external costs arising from landfill and burning are probably lower in sparsely populated areas than in urban areas, while marginal collection costs are likely to be relatively high in the former regions (Berglund 2004). However, the Swedish legislation does not appear to acknowledge this cost-heterogeneity in their instructions to producers. Basically, the sole instruction is that the packaging waste collection should be nation-wide, and in practice entrepreneurs that are active in "high-cost" regions tend to obtain comparably high monetary compensations from the material companies (Hage 2007; Hage and Söderholm 2008). Thus, if our empirical analysis indicates that important regionspecific collection cost elements tend to have negligible impacts on plastic packaging collection rates, this could be interpreted as support for the hypothesis that the spatial cost-effectiveness of the Swedish policy scheme is low.

Second, another key contribution is that we test and control for spatial dependency in waste collection rates. This is relevant when using data collected with references to location, one observation associated with location $i$ will tend to depend on other observations at locations $i \neq j$ (e.g., Anselin 1988; LeSage 1999). In the household packaging waste case there may be several reasons why recycling outcomes in one municipality can be influenced by policies and practices used in neighboring municipalities. For instance, in some instances neighboring municipalities have started jointly owned waste companies, thus implying that information, collection systems and perhaps even other policies may be standardized in the greater region. Moreover, neighboring municipalities may also meet and exchange experiences, and in this way influence each other's policies and in turn collection rates. If such spatial interactions exist ordinary least square (OLS) methods produce parameter estimates that are biased and inefficient, and for this reason we employ spatial econometric methods that explicitly address the incorporation of spatial autocorrelation in the econometric estimations. 


\section{Data sources and definitions}

In this paper we model the household plastic packaging collection rate of a municipality as the annual collection in terms of used plastic packaging in kg per inhabitant (however excluding the deposit-driven PET-bottle collection system). Cross sectional data across 282 Swedish municipalities for the year 2005 are used in the estimations. Our focus on this particular year is motivated by the availability of data, not least that covering the important role of recycling infrastructure, such as the presence of curbside recycling as well as the intensity of drop-off stations.

The determinants of the collection rate can be grouped into five main categories: local policy instruments, geographical, demographic and socio-economic conditions, environmental preferences and the nature of the collection entrepreneurs engaged in each municipality. Table 1 summarizes the variables used, while "Appendix A" shows descriptive statistics. Information on some of the independent variables was not available for 2005, and in these cases we had to revert to information for adjacent years. Overall, though, this should not be a major problem since most of the variables used-including the policy-related ones (e.g., waste management fees) — have been very stable over time.

The selection of independent variables has been heavily influenced by a review of the existing literature. We first note that Swedish municipalities have implemented different types of waste handling fees. A large majority of the municipalities use subscription programs, i.e., volume-based pricing. All volume-based programs in Sweden are designed as subscription programs and include the opportunities to subscribe to: (a) longer garbage collection intervals and hence pay less; (b) share garbage container and the garbage fee with neighbours; and (c) a specific size of the garbage container. The remaining nine percent of the municipalities had (in 2005) implemented weight-based fees for household waste collection. We anticipate that weight-based fees are more effective in increasing recycling rates since the affected household faces a marginal price for every unit of unsorted waste. ${ }^{2}$ The majority of the empirical literature finds that unit-pricing increases the recycling levels (e.g., Fullerton and Kinnaman 1996; Callan and Thomas 1997; Dijkgraaf and Gradus 2004; Kipperberg 2006; Ferrara and Missios 2005). In the empirical analysis we include a dummy variable that equals one (1) for those municipalities that employ a weight-based fee (and zero otherwise).

We also use a dummy variable to examine the influence of the presence of curbside recycling for plastic packaging in the case of single-family dwellings. Clearly, such arrangements ought to (ceteris paribus) have a positive impact on collection rates. This is also found in the literature that controls for the presence of curbside recycling

\footnotetext{
2 The marginal price in the subscription programs will instead be quite rough. For example, the household could change the size of the waste bin and hence pay less but there are at least two problems associated with this strategy. First, the flexibility in the size of the waste bin is not high. Second, households need to notify the local authorities in advance when they want to change bin size. Consequently, a household that wants to be certain that it can manage weekly variations in the waste generation has an incentive to choose a waste bin that can cope with more than the average trash production. Hence, in an average week there will be few incentives to reduce waste generation by recycling more. An additional explanation is that under a subscription program you could also use your neighbors' waste bins if they have free space. None of these problems will exist if the households must pay based on the weight of the waste generated.
} 
Table 1 Variable definitions and sources

\begin{tabular}{lll}
\hline Variables & Definitions & Sources \\
\hline
\end{tabular}

\section{Dependent variable}

Plastic Household plastic packaging waste collected per

Staaf (2006) resident in $\mathrm{kg}, 2005$

Independent variables

(a) Policy variables
Feewe Dummy for weight-based waste fees in 2005, 1 if yes and 0 if no.

Curbside Dummy for curbside collection of plastic packaging in private houses (single-family dwellings) in 2005, 1 if yes and 0 if no.

Drop

The number of household plastic packaging recycling stations per 1000 residents in 2005 (controlling for the urbanization rate)

(b) Geographical and demographic variables

$\begin{array}{ll}\text { Dist } & \text { Distance between each municipality and the nearest } \\ \text { plastic recycling industry (km) in } 2005 \\ \text { Urb } & \text { Urbanization rate, i.e., the share of the population living } \\ & \text { in densely populated areas as of December, } 31,2004 . \\ & \text { A densely populated area is defined as a group of } \\ & \text { buildings not more than } 200 \text { meters apart from each } \\ & \text { other and having at least } 200 \text { inhabitants }\end{array}$

(c) Socio-economic variables

$\begin{array}{ll}\begin{array}{l}\text { Age } \\ \text { Inc }\end{array} & \begin{array}{l}\text { Average age of the population as of December, 31, } 2004 \\ \text { Average income for people between } 20 \text { and } 64 \text { years as } \\ \text { of December 31, 2003 (kSEK) }\end{array} \\ \text { Edu } & \begin{array}{l}\text { People with at least 3-years university degree divided by } \\ \text { total population (\%) as of December, 31, 2003 }\end{array} \\ \text { Unemp } & \text { Open unemployment rate for people between } 16 \text { and } 64 \\ & \text { years in 2005, annual average (\%) } \\ \text { SFD } & \text { The share of single-family dwellings in } 2005(\%) \\ \text { Tim } & \text { Total immigrants, foreign born outside the Nordic } \\ & \text { countries as a share of total population (\%) as of } \\ \text { Dewim } & \text { Necember, 31, 2004 } \\ & \text { Sew immigrants, foreign citizens with 0-4 years in } \\ & \text { 3weden as a share of total population as of December, }\end{array}$

Villaägarna (2006)

Villaägarna (2006), and Mattson (2006)

Funck (2006), and SCB (2005a)

SRA (1999)

KFAKTA (2006)

SCB (2005a)

SCB (2005a)

SCB (2005a)

KFAKTA (2006)

KFAKTA (2006)

AMS (2006)

SCB (2005b)

KFAKTA (2006)

SCB (2005a) 
Table 1 continued

\begin{tabular}{|c|c|c|}
\hline Variables & Definitions & Sources \\
\hline \multicolumn{3}{|c|}{ (d) Environmental preferences } \\
\hline Envm & $\begin{array}{l}\text { Dummy for environmental preferences in the } \\
\text { municipality government, } 1 \text { if green party was } \\
\text { represented in the municipality government in } 2003 \text {, } \\
\text { and } 0 \text { if not }\end{array}$ & KFAKTA (2006) \\
\hline Envh & $\begin{array}{l}\text { "Environmental preferences" in households, measured } \\
\text { by the share of votes on the Green party in the } 2002 \\
\text { parliamentary election }(\%)\end{array}$ & SCB (2002) \\
\hline \multicolumn{3}{|c|}{ (e) Collection entrepreneur dummies } \\
\hline$P N E$ & $\begin{array}{l}\text { Dummy for private-owned packaging entrepreneurs } \\
\text { with a nation-wide collection in 2005, } 1 \text { if yes and } 0 \text { if } \\
\text { no }\end{array}$ & PAB (2007) \\
\hline$P R E$ & $\begin{array}{l}\text { Dummy for private-owned packaging entrepreneurs } \\
\text { with a region-wide collection in } 2005,1 \text { if yes and } 0 \text { if } \\
\text { no. }\end{array}$ & PAB (2007) \\
\hline$M R E$ & $\begin{array}{l}\text { Dummy for municipality-owned packaging } \\
\text { entrepreneurs with a region-wide collection in 2005, } 1 \\
\text { if yes and } 0 \text { if no. }\end{array}$ & PAB (2007) \\
\hline$M L E$ & $\begin{array}{l}\text { Dummy for municipality-owned packaging } \\
\text { entrepreneurs with a collection only in one } \\
\text { municipality in } 2005,1 \text { if yes and } 0 \text { if no. }\end{array}$ & PAB (2007) \\
\hline
\end{tabular}

(e.g., Callan and Thomas 1997; Kinnaman and Fullerton 2000; Jenkins et al. 2003; Kipperberg 2006).

Moreover, we have gathered data on the number of recycling drop-off stations for household plastic waste in each municipality. By dividing these numbers with the respective populations (in thousands) and controlling for the urbanization rate, we obtain a measure of the density of drop-off stations for each municipality. The higher this density is, the higher collection rate would be expected.

Several geographical and demographic variables are incorporated. The distance between the municipality center and the plastic recycling industries should affect the transportation costs for the material companies. The longer this distance is, the lower should the incentives be for the material companies to collect household waste. However, as was noted above, in the Swedish case this cost disadvantage may be neutralized by higher monetary compensation levels for the collected household plastic packaging waste. Hage and Söderholm (2008) report that entrepreneurs operating far away from recycling industries and in sparely populated areas obtain a higher fixed compensation for their collection of packaging waste (compared to those operating in densely populated areas). ${ }^{3}$ This is a violation of the cost-effectiveness principle, and suggests that the values of the fixed compensations for plastic packaging waste collection are likely important for explaining differences in collection rates across municipalities. These values are however determined in secret negotiations between

3 The monetary compensation to the collection entrepreneurs consists of one variable and one fixed component. The variable component is officially reported and equally high for all companies that sell plastic packaging waste, while the fixed component varies across different municipalities. 
the material company and the entrepreneurs so we cannot explicitly test this hypothesis in the empirical investigation.

If waste collection in high-cost municipalities receives higher monetary compensation, it is also reasonable to presume that other cost factors will only have minor impacts on reported collection rates. In addition, since we are uncertain about the exact shape of the collection cost function at the municipal level, it is useful to test for the impact of several types of cost indicators. High urbanization rates and population densities imply shorter distances for households and material companies, and higher values should imply lower the transport costs for both households and the collection entrepreneurs (e.g., Sidique et al. 2010). Still, high population urbanization rates and densely populated areas could also drive up land prices and hence the material companies' costs for establishing drop-off stations (e.g., Mazzanti et al. 2011; Gaeta et al. 2017). ${ }^{4}$ This implies the presence of one positive transport cost effect and one negative land cost effect associated with high urbanization rates and population densities, and which of these dominates in practice remains an empirical question. ${ }^{5}$

One hypothesis is that the relationships between population density and urbanization rate on the one hand and the collection costs on the other are non-linear Specifically, the transport cost effect dominates when the municipalities are relatively sparsely populated while in very densely populated cities the land cost effect dominates. At least four explanations for this relationship can be identified. First, in smalland medium-sized cities it is reasonable to assume that the municipalities possess land that could be rented to the material companies at relatively favorable charges, but such cheap land is much scarcer in dense cities. Second, small- and medium-sized cities in Sweden generally have relatively small city centers. Hence, here it is possible for the material companies to establish their recycling centers just outside the city center but still avoid long transport distances from households to recycling centers. In big cities, the establishment of drop-off stations outside the city center implies much longer transport distances for households. Third, the possession of cars is typically less frequent in larger cities and because many use their car for leaving household packaging waste at recycling stations, this could reduce collection rates in congested areas. Fourth, congested cities often have problems with the traffic situation. All in all this suggests that there could also be a negative big city effect. ${ }^{6}$ In the empirical analysis we therefore introduced a dummy variable addressing this possibility (see Table 1). However, as suggested above, the impact of these regional cost differences in collection can be offset by the prevailing pricing policy of the material companies.

Seven socio-economic variables are included in the empirical investigation. After consulting a number of previous studies Schultz et al. (1995) report that the relationship between age and U.S. household recycling efforts appears to be ambiguous, while some

\footnotetext{
${ }^{4}$ Higher land prices also tend to imply higher landfill costs. However, this should not influence the collection costs for Swedish plastic packaging waste since all this waste must be either burnt or recycled.

5 It should be noted that in our data sample of Swedish municipalities the urbanisation rate and the population intensity variables are not highly correlated. The correlation coefficient equals 0.4 .

6 A non-economic explanation for a negative big city effect may be that the impact of social norms, i.e., norms sanctioned (directly or indirectly) by other people (Thogersen 1996), is less pronounced in the more anonymous big cities.
} 
empirical studies find a positive relationship between income rates and recycling rates in developed countries (e.g., Callan and Thomas 1997, 2006; Gaeta et al. 2017). Higher incomes could be correlated with more concern for the environment, and some studies argue that elderly people are more frequent recyclers because this activity tends to be positively affected by conservation habits that tend to be more widespread among older people (e.g., Li 2003). Related to this a number of U.S. studies present evidence in support of a positive relationship between education and household recycling efforts (e.g., Schultz et al. 1995; Callan and Thomas 1997). A higher education level may permit a better understanding of the underlying environmental concerns motivating material recycling, and therefore also enhance the perception of an ethical reward arising from contributing to a better environment (e.g., Czajkowski et al. 2017).

However, recycling can also be a time consuming activity for households, implying that the individual recycling levels will also be influenced by the opportunity costs of the time spent on recycling efforts. This cost will increase with income (and hence education) and be low for retired (elderly) people, thus implying that low-income and older households could (ceteris paribus) recycle more packaging waste. In this respect the rate of unemployment could also matter. The opportunity cost of the time spent on waste packaging sorting is likely to be lower for unemployed people, and one can therefore expect that these will spend relatively more time on waste sorting activities. Nevertheless, the (net) impacts of income, age, education and unemployment on household recycling efforts are a priori ambiguous given that these are affected by both moral concerns and economic trade-offs (see also Söderholm 2010).

Schultz et al. (1995) found no relationship between gender and household recycling efforts, and we test whether this conclusion also holds in the Swedish case. The type of housing may be an important determinant of recycling efforts. It is worth noting that very few single-family dwellings $(S F D)$ in Sweden can benefit from curbside recycling services (and we also control for this service by using the above-mentioned dummy variable). However, it is reasonable to expect that people living in SFDs have more space for storing used packaging, and they are more likely to own a car and also to have easy access to the car compared to people living in multi-family dwellings. This suggests that collection could, ceteris paribus, be higher in areas with a large share of single-family dwellings. However, the fact that rather many multi-family dwellings have access to property-close collection schemes may offset this impact (e.g., Hage et al. 2009; Mattsson et al. 2003). In Sweden, about 46 percent of all multi-family dwellings had packaging waste collection within the property in 2006, while the remaining households in this category had to transport the packaging waste to drop-off stations (SEPA 2006).

Finally on the inclusion of various socio-economic characteristics, we note that immigrants, especially newly-arrived immigrants from outside the Nordic countries, may face difficulties in understanding the language. This makes it reasonable to expect that their participation in packaging collection programs are generally lower than for people who have lived in Sweden for a longer time. Dijkgraaf and Gradus (2004) also find that there is a negative relationship between immigrants and recycling in Netherlands, while Hage and Söderholm (2008) only report such a relationship in the case of newly arrived immigrants. In this paper we therefore make a distinction 
between the shares of immigrants in the municipalities in general (Tim) and the share of newly arrived immigrants Newim.

As was noted above, concern for the environment may be likely to influence plastic packaging waste collection rates. In the empirical investigation we add two independent variables that attempt to address the strength of environmental preferences in the respective municipalities. The more emphasis the local government puts on environmental issues the more likely it is that it will attempt to facilitate packaging collection. There exist a number of ways through which this can be achieved. For instance, more effective waste information should naturally increase the packaging collection levels. The municipalities also rent sites for the recycling stations and provide building permits. $^{7}$

In the empirical analysis we use the influence of the Green party in the local government as a proxy for the environmental preferences in the local policy arena. While this variable does address the direct influence of Green party politics at the local level, it is also reasonable to believe that households that are concerned about the environment should be motivated to sort packaging waste (e.g., Schultz et al. 1995; Hornik et al. 1995; Söderholm 2010). We test this hypothesis by employing the share of votes on the Green party. While this is only a rough proxy for environmental concern, one should note that strong support for the Green party may indicate the presence of strong social norms in household recycling. People-including those that put their votes on other parties - may feel that other households expect them to perform waste sorting activities (Bruvoll and Nyborg 2004; Czajkowski et al. 2017). The influences of the two Green party variables on recycling outcomes are thus assumed to work through fundamentally different channels, which are not necessarily closely linked to each other.

Finally, the nature of the collection entrepreneurs that are active in the various municipalities differ; they may be privately owned or owned by the local authorities and some will be active in many municipalities while others only cover one municipality (e.g., Hage and Söderholm 2008). We add intercept dummy variables, $D_{n}(n=1 \ldots 3)$, for three types of collection entrepreneurs while a fourth one, MLE, is used as a reference category. These dummies are control variables that could, for instance, capture the presence of differences in collection productivity, incentive structures, strategies and/or negotiation skills across entrepreneurs. As will be suggested below, in some cases they may also reflect regional differences that are not entirely addressed by the other independent variables in the econometric analysis.

\section{Model specification and econometric issues}

There exist few a priori theoretical reasons to specify a certain functional form for the model to be estimated, and for this reason we follow previous studies (e.g., Callan

\footnotetext{
7 There exists also an important economic incentive for the Swedish municipalities to support the packaging collection. In 2000, Sweden began to tax waste disposal and in 2002 a prohibition to deposit waste that can be incinerated or recycled was introduced.
} 
and Thomas 1997) and specify a linear econometric model. ${ }^{8}$ As was noted above, it is however reasonable to suspect that both municipalities and collection entrepreneurs may be influenced by the performance and the policy measures of neighboring municipalities. Spatial dependence of this type calls for spatial econometric methods.

In a spatial context the dependence among two municipalities may, and usually does, operate in both directions, and a common simplification is first to assume equally strong dependence in both directions. A spatial weights matrix, $W$, is constructed to proxy for these multiple dependencies between observations that are to be included in the estimation. This matrix is assumed to be a matrix of known elements and in which all elements on the main diagonal equal zero. There are various ways to construct this matrix; the most common is a binary approach based on unit contiguity or a matrix based on some distance decay function. The spatial weights matrix used in this paper is defined as a row-standardized inversed squared distance matrix, with a distance cut-off at the samples first quartile $(182.3 \mathrm{~km}){ }^{9}$

The map of Sweden displayed in Fig. 2 indicates how plastic packaging collection rates in different municipalities are related to the weighted average collection rate in the neighbouring municipalities. For example, the low-high label specifies that a given municipality collects relatively low amounts of plastic packaging waste (per person) but their neighbours report relatively high collection rates. Figure 2 also illustrates that Sweden appears to have several plastic packaging collection "clusters", some with low and some with high rates of collection.

This strengthens our a priori suspicion that there exists a spatial dependence in the plastic packaging collection. Still, the map does not provide any information if these observations are statistically significant nor an explanation for how the pattern was created or can be changed, thus motivating the use of spatial econometric methods. Exploratory data analysis is a good starting point in order to test for spatial dependence (spatial autocorrelation). In this way we may confirm or reject the hypothesis that objects of similar values are more clustered than by pure chance.

At our disposal are a couple of global tests for spatial autocorrelation, such as Moran's I and Geary's C (Moran 1948; Geary 1954; Cliff and Ord 1973, 1981). The notion of global tests refers to the fact that they consider the overall data pattern and only return a single value which either confirms or rejects the hypothesis. No specific information is, however, given about the prevailing pattern. When this is of interest, local tests may be used (Getis and Ord 1992; Ord and Getis 1995, 2001; Anselin 1995). For our purposes the Moran's I for the tested matrices is presented in "Appendix B". According to these results, the chosen matrix, i.e., the row-standardized inversed squared distance matrix with a distance cut-off at the samples first quartile, and the rowstandardized nearest neighbors' matrices detect the highest spatial autocorrelation.

\footnotetext{
8 We also tested a log-linear specification, and the overall results were fairly similar to the ones reported here. Moreover, employing a logarithmic form of the dependent variable did not lead to fewer problems connected with non-normally distributed residuals.

9 This weight matrix was also tested by using the inverse distance. Additional cut-off distances (i.e., 2 and 3 quartiles) by using inverse distance and inverse squared distance, and 5 respectively 10 nearest neighbours' weight matrices, were also tested (all row-standardized).
} 
Fig. 2 Moran Scatterplot Map for Plastic Packaging Waste Collection in Sweden. Note: The spatial weight matrix used when constructing this map is defined as a row-standardized inversed squared distance matrix, with a distance cut-off at the samples first quartile $(182 \mathrm{~km})$. The coloured boxes indicate the plastic collection rate in a chosen municipality (first word) and in their neighbours (second word)

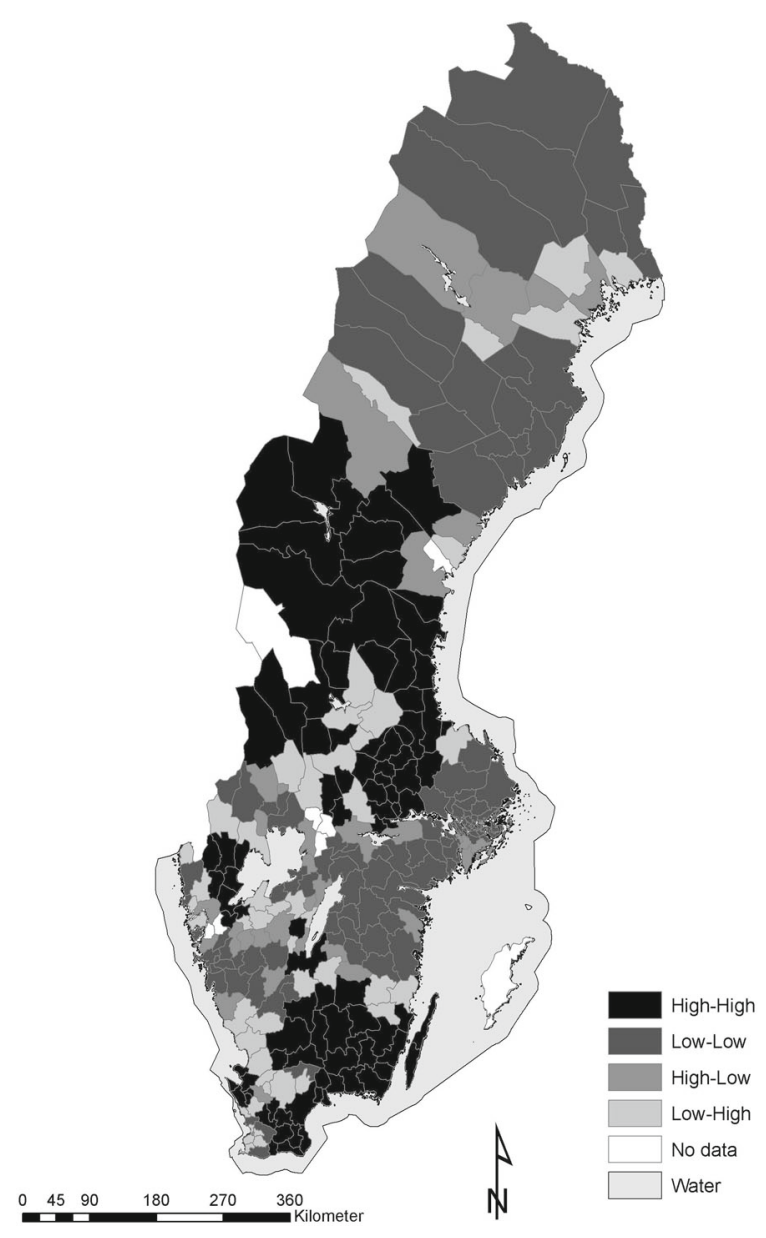

The choice of the former matrix is motivated by the regression diagnostic (see further Section 4).

The next step is to solve for spatial dependence in a regression analysis. Two kinds of spatial dependencies should be considered. ${ }^{10}$ The first arises when variables of adjacent observations move together due to common or correlated unobservable variables, i.e., lack of stochastic independence between observations. This problem is discussed at length in Cliff and Ord (1972, 1973). Equation (1) displays a standard linear regression model but where a partition of the error term into two parts, together with a given spatial weights matrix $W$, solves the spatial dependence problem. The model is known as the Spatial Error Model.

$$
y=X \beta+\varepsilon
$$

\footnotetext{
10 We also tested the so-called Spatial Durbin Model to avoid omission of spatially lagged explanatory variables causing spatially correlated residuals. However, the results were not improved.
} 


$$
\varepsilon=\lambda W \varepsilon+\xi
$$

where $\lambda$ is the spatial autocorrelation coefficient and $\xi$ is a vector of independently and identically distributed errors (i.i.d.) errors. In our case this could be reflected in the fact that the collection rate in one municipality is a function of municipalityspecific characteristics but also of omitted variables in neighbouring municipalities. Coefficient estimates that are based on ordinary least squares (OLS) methods would in this case be inefficient.

The second problem relating to spatial dependence is present when spatial correlation in the dependent variable across observations exists. Such dependence leads to both biased and inefficient estimates (e.g., Anselin 1988). This problem may be solved by including the dependent variable of the other observations on the right hand side of the equation lagged by a spatial weights matrix. This model is known as the Spatial Lag Model.

$$
y=\rho W y+X \beta+\varepsilon
$$

where $y$ is the dependent variable (i.e., plastic in equation (1)), $\rho$ is a spatial autoregressive coefficient, $X$ is a vector of independent variables, and $\varepsilon$ is a vector of i.i.d. errors. As usual, additional problems during estimation, such as heteroskedasticity, may occur. These problems can be solved similarly as by standard econometric methods. ${ }^{11}$

The classical estimation routine towards a proper model specification under the potential influence of spatial dependence is provided in Florax et al. (2003). The initial model is estimated by means of OLS. The residuals are then used to test the hypothesis of no spatial dependence caused by an omitted spatial lag or by spatially autoregressive errors by use of two Lagrange Multiplier tests, the LM-lag test and the LM-error test (e.g., Anselin 1988; Burridge 1980). When this null hypothesis cannot be rejected, i.e., no spatial dependence is at hand, the results based on OLS may be used. However, in the event that the hypothesis is rejected, a new model should be estimated. The proper model is indicated by the most significant LM test. In case that only the LM-lag test is statistically significant, the next step would be to estimate a Spatial Lag Model or a Spatial Error Model if the opposite results are indicated. The model estimations were performed using the SPACESTAT software.

Finally, it should be acknowledged that even though the parametric approach is the dominant paradigm in spatial econometrics, this approach has limitations. Specifically, any parametric model is limited to specific forms of spatial variation of the parameters. They may not be suitable for more general forms of spatial heterogeneity of model parameters, such as when the variation of the parameters is continuous over space and

11 Problems of spatial heterogeneity or structural instability may be present so that the parameter estimates may differ across space. The data should then be divided into a number of spatial regimes to yield one parameter estimate per regime. It has been suggested that we should use the different collectors as ground for the regimes. Unfortunately some of the collectors are fairly small, which would mean estimation difficulties with a limited number of observations or that we would have to group some of the collectors in a more or less ad hoc fashion. Another option would have been to use a geographical partition, for instance north vs. south. But, as can be seen in Fig. 2, there is no clear north/south pattern that would motivate such a partition, and some of the entrepreneurs are active throughout Sweden. This led us not to pursue this option further. 
depends on coordinates, and when the functional form of the relationship between the dependent variable and the regressor is unknown (e.g., Basile and Minguez 2017).

\section{Empirical results and discussion}

The estimated coefficients are presented in Table 2, and the results from the OLS estimations are displayed in the second column. The null hypothesis of homoskedasticity is not rejected by the Koenker-Basset test but the assumption of normally distributed residuals is rejected by the Jarque-Bera test. ${ }^{12}$ This calls for caution since tests for spatial dependence are sensitive for non-normally distributed residuals. The value of Moran's I is statistically significant at the one percent level, and we can therefore reject the null hypothesis of no spatial dependence. Moreover, despite the lack of normality, the LM-tests indicate that spatial lag dependence is present. ${ }^{13}$ We therefore estimate the spatial lag model using Maximum Likelihood (ML). This is done despite its weakness in connection with non-normally distributed residuals. However, the benefit is that it provides the most insight in the form of tests available on our way towards a final model.

The results from the ML estimation are given in the third column of Table 2. The spatial lag parameter $\rho$ is positive and highly statistically significant, i.e., the collection of plastic packaging in one municipality is positively influenced by the amount collected in nearby municipalities. The last two tests in the ML column verify that we have done a correct specification by including a spatial lag and not solved the spatial dependence problem by a spatial error model. On the other hand, the null hypothesis of homoskedasticity is also now rejected, something which may be due to the problem of non-normally distributed residuals.

In order to solve the problem of heteroskedasticity and non-normally distributed residuals a viable solution is to use a robust IV estimation (2SLS). The instruments used to estimate this model are spatially lagged exogenous variables as suggested by Kelejian and Robinson (1992). The resulting coefficients are given in the fourth column. We here note that the estimate for the spatial lag parameter $(\rho)$ increases compared to the ML estimate.

In the fifth and final column we instead present a model estimated by bootstrap $^{14}$ with 999 permutations, another good alternative to ML in situations where heteroskedasticity may be present and the normality assumption is possibly invalid

\footnotetext{
12 The problem with non-normally distributed residuals can sometimes be solved by using the logarithm of the dependent variable in the regression. However, when testing for this, the Jarque-Bera in this case became even more statistically significant.

13 The standard LM-tests for spatial lag and error are both highly significant, thus confirming the problem with spatial autocorrelation. As in this case, when both standard LM-tests are statistically significant, we should consider the robust LM-tests for choosing the appropriate specification of the model. However, none of these are highly significant (the robust LM-test is significant at the 12 percent level). This implies that we should return to the standard LM-test and choose the most significant test. When doing so we could see that the standard test for spatial lag is more significant $(9.64>7.33)$. As a result, we will use a spatial lag model in the estimation.

14 The bootstrap is a robust estimator that uses random resampling technique for statistical inference. The procedure in this bootstrap is based on residuals and is suggested by Freedman and Peters (1984a, b). First, an IV-estimation is done and the vector of estimated residuals $(\boldsymbol{e})$ is calculated. Second, we use $\boldsymbol{e}$
} 


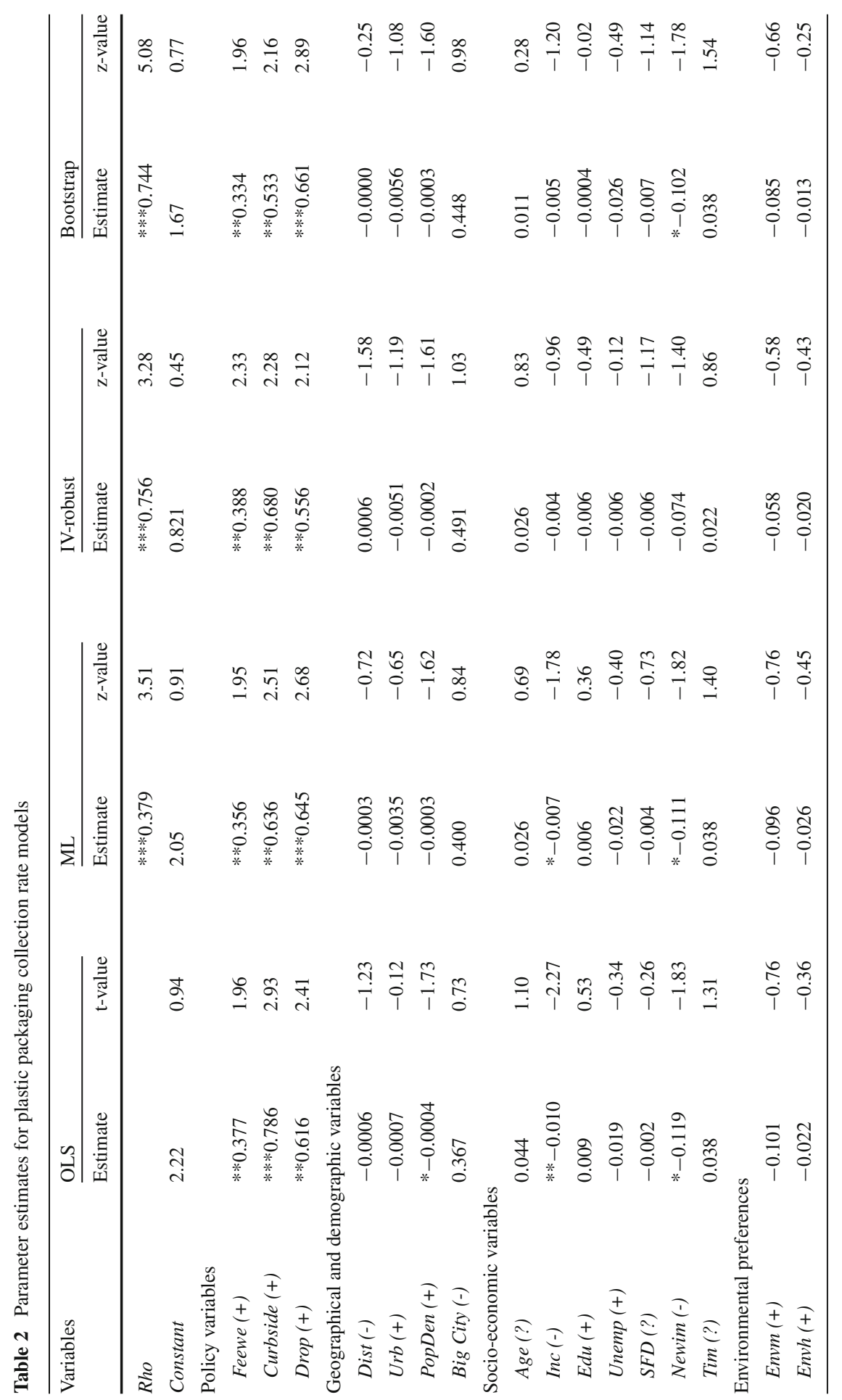




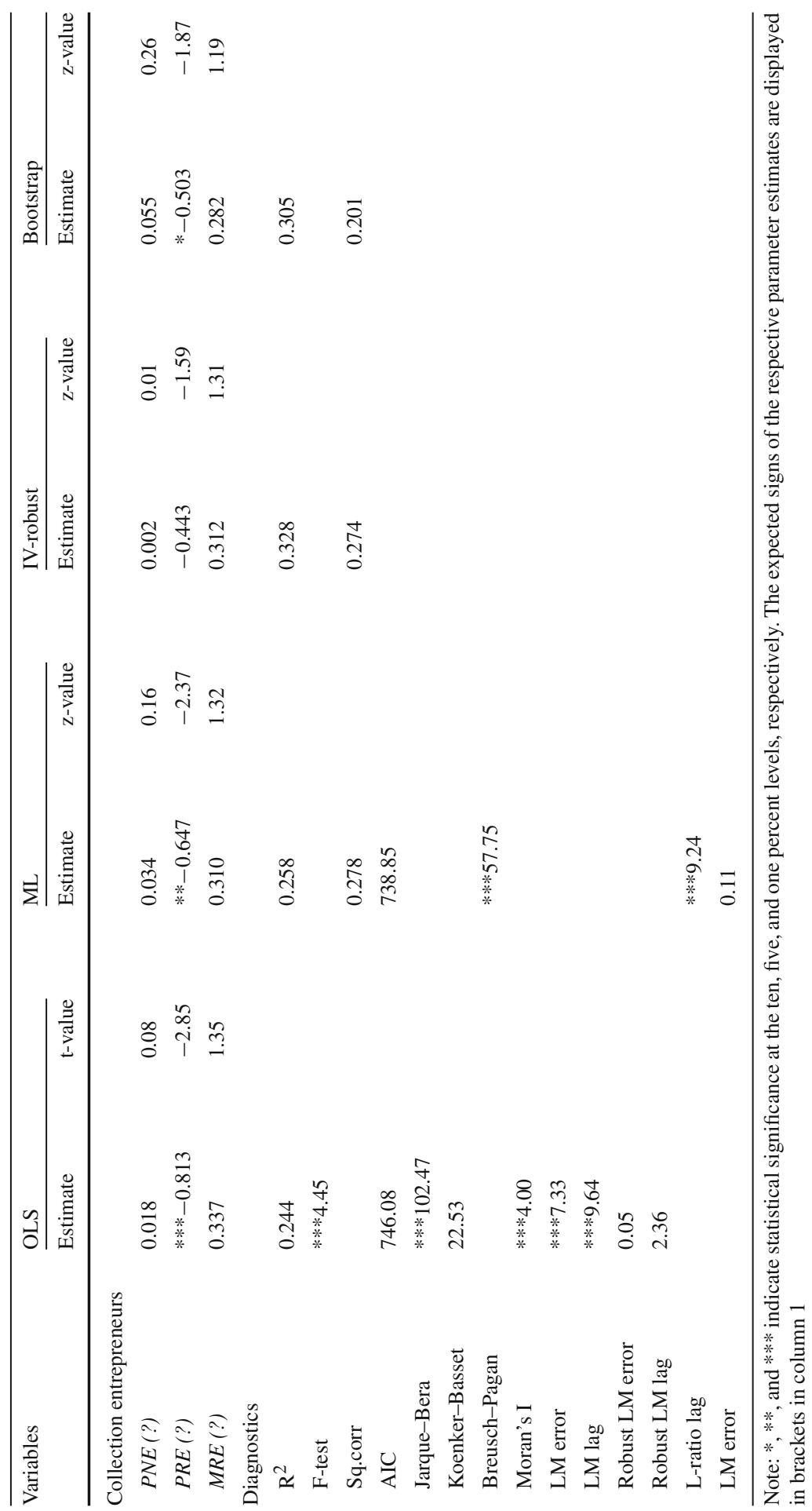


(Freedman and Peters 1984a, b; Anselin 1988, 1990). Overall, the results are similar so we may conclude that the results are fairly robust for different model specifications. ${ }^{15}$

The parameter estimates for the policy variables display interesting results. The coefficient for weight-based fee is as expected positive and statistically significant at the 5 percent level. The results suggest that municipalities that have introduced weight-based fees report on average $0.35 \mathrm{~kg}$ higher collection rates per inhabitant. This amounts to around 18 percent of the average collection rate in 2005. However, even though the introduction of such fees could be an effective method for increasing collection rates, our results do not have anything to say about whether such policies pass a cost-benefit test or not. The potential for undesirable side-effects of weightbased fees must also be acknowledged; they can provide households with an incentive for illegal waste disposal, and empirical research suggests that such an outcome cannot be ignored (Fullerton and Kinnaman 1996; Dahlén et al. 2007). It is also important to assess the administrative costs of introducing such a system if economic efficiency is to be ensured (e.g., Kinnaman 2006).

Furthermore, the coefficients for the curbside collection variable and the variable addressing the density of plastic packaging recycling stations in each municipality are both positive and statistically significant at the five percent level. These results suggest that municipalities that make use of a curbside collection system tend to on average recover more plastic packaging waste per resident than municipalities without such schemes.

Specifically, while our investigation does not test explicitly for causal effects they suggest that municipalities that have introduced curbside recycling have collection rates that tend to be $0.5 \mathrm{~kg}$ higher per inhabitant compared to municipalities lacking such schemes. The empirical results thus suggest that measures to facilitate recycling efforts by creating the infrastructural and logistic mechanisms that enable people to translate any environmental motivations and norms into recycling action may be effective (see also Thogersen 1996, 2003; Hage et al. 2009; Abbott et al. 2011).

Overall the results show that the geographical and demographic variables, i.e., proxies for the marginal collection costs at the municipal level, appear to have had limited correlation with the collection rates. Most notably, the three coefficients representing urbanization rate, population density and "big city", respectively, are all found to be statistically insignificant. As was noted above, this supports the plausible notion that the collection of household plastic packaging waste has not been performed in a cost-effective manner. One explanation may be that the pricing negotiations between the material companies and the collection entrepreneurs have led to a situation where

\footnotetext{
Footnote 14 continued

for generating a vector of pseudo residuals $\left(e^{*}\right)$ by drawing them random with replacement; in our case this is done 282 times. Third, pseudo data for the vector of independent variable $\left(y^{*}\right)$ is calculated by using the vector of exogenous variables $(\boldsymbol{X})$, the estimated parameters from the IV-estimation, and the $\boldsymbol{e}^{*}$. Fourth, new parameter estimates are now obtained by using the IV estimation on $\boldsymbol{y}^{*}$ and $\boldsymbol{X}$. This is the first permutation, and this step is repeated 998 times. Finally, the bootstrap parameter estimate is then calculated by the mean values from these permutations.

15 This is also valid if estimating the model by using the row standardized 5 nearest municipalities weight matrix and bootstrap technique. For example, all the signs for parameter estimates are unchanged and the sizes for the parameter estimate are similar.
} 
entrepreneurs that serve "high-cost" municipalities obtain a higher fixed compensation compared to the entrepreneurs that are active in municipalities that tend to score high on, for instance, urbanization rate and population density.

Table 2 shows that the socio-economic variables overall add little to our understanding of plastic packaging waste collection rates, and to some extent this may be due to the fact that these variables show limited variation across the different municipalities (see "Appendix A"). For instance, in the cases of age, unemployment rate, income, education and share of single-family dwellings we find no statistically significant results in the robust IV estimation and Bootstrap estimations. However, the coefficient for share of new immigrants has the expected negative sign, but it is only statistically significant at the ten percent level in almost all model estimations. A possible explanation for a negative correlation in this case could be that when immigrants arrive to Sweden they are not well acquainted with Swedish laws and norms and neither are they able to understand the language very well. This has negative impacts on waste sorting activities. Still, over time the newcomers learn the language and pick up social norms of behavior, and the results suggest that immigrants in general may be just as good recyclers of household plastic waste as Swedes in general (see also Hage and Söderholm 2008). ${ }^{16}$

Our fourth category of independent variables, environmental preferences, does not help much in explaining collection outcomes. Specifically, the coefficients for Green party representation in the local government and for Green party support among households are both statistically insignificant. Finally, the use of collection entrepreneur dummies appears to explain some of the variance in household plastic packaging waste collection, but only in the case of private regionally-based entrepreneurs, which (ceteris paribus) report lower collection rates than the other categories of collection entrepreneurs. One plausible explanation behind this result is that quite a few of the private entrepreneurs operate in sparsely populated areas in the most northern parts of Sweden. In addition, it has sometimes been claimed that a few of these enterprises have been ineffective in terms of emptying recycling containers and generally maintaining the quality and cleanliness of the drop-off stations.

\section{Concluding remarks and implications}

The purpose of this paper was to analyze the determinants of inter-municipality differences in the collection of household plastic packaging waste in Sweden. We used spatial econometric methods and the results revealed that spatial interaction is present in the data used, and when we controlled for this, and attempt to address the presence of heteroscedasticity, we obtain results that are fairly robust across different model specifications. The spatial lag parameter suggested that the collection of household plastic packaging per capita has been positively related to the spatially weighted average of the collection per capita in neighboring municipalities. In other words, the probability that the collection of packaging waste is high increases if the neighboring municipalities collect high degrees of the household plastic packaging. This may be the result

16 The correlation coefficient between the two immigration variables was just above 0.5 percent, thus possibly adding to the statistically significant results for these variables. 
of cross-municipality interactions and cooperation or simply because municipalities and collection companies copy-cat policies or organizational solutions.

Overall the results suggest that policy variables rather than geographical, demographic and socio-economic factors have been correlated with plastic packaging waste collection rates. First, municipalities that have introduced weight-based waste handling fees tend to have had higher collection rates. Second, making household recycling of plastic packaging easier by introducing curbside recycling and/or increasing the density of recycling centers also appears to be correlated with higher collection rates. Thus, we find that facilitating means of this kind could increase the recycling efforts undertaken by citizens. It is however imperative to stress the importance of weighing the administrative costs of operating, for instance, curbside recycling against the social benefits of having such schemes in place before supporting wide-spread adoption of these means (Kinnaman 2006). Furthermore, our results primarily show the presence of statistical correlation between policy measures and recycling outcomes, and should not be interpreted as causal effects.

The results displayed that the different proxies for the marginal costs of plastic packaging collection did not exert correlations with collection outcomes. A reasonable explanation for this is that the compensation from the material companies varies depending on region, and this tends to reduce regional cost differences in collection. This indicates in turn that the Swedish society could save economic resources by paying more attention to regional cost differences. Nevertheless, purely on the basis of our study it is difficult to outline strong policy recommendations. A move to a more cost-effective collection scheme would have both pros and cons. For instance, we have not here considered the transaction costs involved, i.e., the costs of administering, monitoring and enforcing a new system. Still, these costs need not be high. The authorities must not necessarily decide upon different collection targets for dense and sparsely populated regions, respectively, and then enforce each of these. It may be enough to reform the compensation scheme, implement uniform compensation levels, and permit these economic incentives to determine where the collection will be made. One of the major drawbacks of a cost-effective scheme in which spatial cost differences matter may rather lie in the notion that there could be a trade-off between the cost-effectiveness and the legitimacy of such a policy. If people as well as politicians feel committed to waste recycling because it is one way of contributing to public environmental goods, they may have a negative attitude towards a policy that encourages spatial differences in collection efforts.

Finally, although this paper has shed some amount of light on the regional heterogeneity of recycling outcomes in the case of plastic packaging waste, there are limitations to our analysis that should deserve increased attention in future research. Research should better address the issue of endogeneity in the independent variables; the variables used to operationalize the recycling policy instruments may not be exogenous to recycling outcomes (e.g., due to policies responding to actual outcomes). Moreover, we have also pointed out the potential for using semi-parametric approaches in the study of regional waste and recycling outcomes; non-parametric can work even with limited data sets. Finally, at a more general level, future research on the regional dimensions of waste management policy, could also benefit from explicitly addressing differences in the regional heterogeneity across various countries. 
Acknowledgements Financial support from the Swedish Environmental Protection Agency (SHARP research program) is gratefully acknowledged. Earlier versions of the paper have benefited from comments provided by Chris Gilbert, Tomas Ekvall, Henrik Hammar, Anders Lagerkvist, Åsa Löfgren, David Maddison, Wade Martin, Simon McDonnell, Marian Radetzki, and John E. Tilton. Any remaining errors, however, reside solely with the authors.

Open Access This article is distributed under the terms of the Creative Commons Attribution 4.0 International License (http://creativecommons.org/licenses/by/4.0/), which permits unrestricted use, distribution, and reproduction in any medium, provided you give appropriate credit to the original author(s) and the source, provide a link to the Creative Commons license, and indicate if changes were made.

\section{Appendix A}

See Table 3.

Table 3 Descriptive statistics

\begin{tabular}{lllll}
\hline Variables & Mean & Std. dev & Min & Max \\
\hline $\begin{array}{l}\text { Dependent variable } \\
\quad\end{array}$ & 1.97 & 0.97 & 0.04 & 5.71 \\
$\quad \begin{array}{l}\text { Plastic } \\
\text { Policy variables }\end{array}$ & & & & \\
$\quad$ Feewe (D) & 0.09 & 0.28 & 0.00 & 1.00 \\
Curbside (D) & 0.05 & 0.22 & 0.00 & 1.00 \\
Drop & 0.57 & 0.26 & 0.09 & 1.86
\end{tabular}

Geographical and demographic variables

$\begin{array}{lllll}\text { Dist } & 178 & 151 & 10.0 & 940 \\ \text { Urb } & 73.6 & 15.5 & 31.0 & 100 \\ \text { PopDen } & 129 & 429 & 0.20 & 4075 \\ \text { BigCity (D) } & 0.04 & 0.20 & 0.00 & 1.00\end{array}$

Socio-economic variables

$\begin{array}{lllll}\text { Age } & 42.0 & 2.27 & 36.2 & 47.3 \\ \text { Inc } & 216 & 23.2 & 178 & 393 \\ \text { Edu } & 12.3 & 6.14 & 5.00 & 48.0 \\ \text { Unemp } & 4.28 & 1.26 & 1.80 & 8.60 \\ \text { SFD } & 62.3 & 15.3 & 2.66 & 93.1 \\ \text { Tim } & 5.64 & 3.79 & 1.20 & 27.6 \\ \text { Newim } & 1.61 & 1.05 & 0.20 & 7.60\end{array}$

Environmental preferences

$\begin{array}{lllll}\text { Envm }(D) & 0.24 & 0.43 & 0.00 & 1.00 \\ \text { Envh } & 3.89 & 1.16 & 0.90 & 8.80\end{array}$

$D$ denotes the use of $(1 / 0)$ dummy variables

Collection entrepreneur dummies

$\begin{array}{lllll}\operatorname{PNE}(D) & 0.65 & 0.48 & 0.00 & 1.00 \\ \operatorname{PRE}(D) & 0.12 & 0.32 & 0.00 & 1.00 \\ \operatorname{MRE}(D) & 0.16 & 0.37 & 0.00 & 1.00 \\ \operatorname{MLE}(D) & 0.07 & 0.25 & 0.00 & 1.00\end{array}$




\section{Appendix B}

\section{See Table 4}

Table 4 Moran's I test of spatial correlation in plastic packaging collection

\begin{tabular}{|c|c|}
\hline Weight matrix & Moran's I \\
\hline $\begin{array}{l}\text { The row-standardized inversed distance matrix, with a distance cut-off at the samples first } \\
\text { quartile }\end{array}$ & $* * * 0.10$ \\
\hline $\begin{array}{l}\text { The row-standardized inversed squared distance matrix, with a distance cut-off at the } \\
\text { samples first quartile }\end{array}$ & $* * * 0.18$ \\
\hline $\begin{array}{l}\text { The row-standardized inversed distance matrix, with a distance cut-off at the samples } \\
\text { second quartile }\end{array}$ & $* * * 0.06$ \\
\hline $\begin{array}{l}\text { The row-standardized inversed squared distance matrix, with a distance cut-off at the } \\
\text { samples second quartile }\end{array}$ & $* * * 0.15$ \\
\hline $\begin{array}{l}\text { The row-standardized inversed distance matrix, with a distance cut-off at the samples third } \\
\text { quartile }\end{array}$ & $* * * 0.05$ \\
\hline $\begin{array}{l}\text { The row-standardized inversed squared distance matrix, with a distance cut-off at the } \\
\text { samples third quartile }\end{array}$ & $* * * 0.15$ \\
\hline The row-standardized 5 nearest municipalities matrix & $* * * 0.25$ \\
\hline The row-standardized 10 nearest 10 municipalities matrix & $* * * 0.16$ \\
\hline
\end{tabular}

The chosen matrix is written in italics, and $* * *$ indicate statistical significance at the one percent level

\section{References}

Abbott, A., Nandeibam, S., O'Shea, 1: Explaining the variation in household recycling rates across the UK. Ecol. Econ. 70, 2214-2223 (2011)

Abrate, G., Ferraris, M.: The environmental kuznets curve in the municipal solid waste sector. HERMES Working Paper No. 1, Fondazione Collegio Carlo Alberto, Moncalieri, Italy (2010)

Anselin, L.: Spatial Econometrics: Methods and Models. Kluwer Academic Publishers, Dordrecht (1988)

Anselin, L.: Some robust approaches to testing and estimation in spatial econometrics. Reg. Sci. Urban Econ. 20, 141-63 (1990)

Anselin, L.: Local indicators of spatial association-LISA. Geogr. Anal. 27(2), 93-115 (1995)

Basile, R., Minguez, R.: Advances in spatial econometrics: parametric vs. semiparametric spatial autoregressive models. In: Commendatore, P., et al. (eds.) The Economy as a Complex Spatial System, pp. 81-106. Springer, Berlin (2017)

Berglund, C., Söderholm, P.: An econometric analysis of global waste paper recovery and utilization. Environ. Resour. Econ. 26(3), 429-455 (2003)

Berglund, C.: Spatial cost efficiency in waste paper handling: the case of corruga-ted board in Sweden. Resour. Conserv. Recycl. 42(4), 367-387 (2004)

Bruvoll, A., Nyborg, K.: The cold shiver of not giving enough: on the social cost of recycling campaigns. Land Econ. 80(4), 539-549 (2004)

Burridge, P.: On the Cliff-Ord test for spatial correlation. J. R. Stat. Soc. B 42, 107-108 (1980)

Callan, S.J., Thomas, J.M.: The impact of state and local policies on the recycling effort. East. Econ. J. 23(4), 411-423 (1997)

Callan, S.J., Thomas, J.M.: Analyzing demand for disposal and recycling services: a systems approach. East. Econ. J. 32(2), 221-240 (2006)

Cliff, A., Ord, J.K.: Testing for spatial autocorrelation among regression resi-duals. Geogr. Anal. 4, 267-284 (1972)

Cliff, A.D., Ord, J.K.: Spatial Autocorrelation. Pion Limited, London (1973)

Cliff, A.D., Ord, J.K.: Spatial Processes Models and Applications. Pion Limited, London (1981) 
Czajkowski, M., Hanley, N., Nyborg, K.: Social norms, morals and self-interest as determinants of proenvironment behaviours: the case of household recycling. Environ. Resour. Econ. 66, 647-670 (2017)

D’Amato, A., Mazzanti, M., Nicolli, F.: Waste and organized crime in regional environments. How waste tariffs and the mafia affect waste management and disposal. Resour. Energy Econ. 41, 185-201 (2016a)

D’Amato, A., Mancinelli, S., Zoli, M.: Complementarity vs substitutability in waste management behaviors. Ecol. Econ. 123, 84-94 (2016b)

Dahlén, L., Vukicevic, S., Meijer, J.-E., Lagerkvist, A.: Comparison of different collection systems for sorted household waste in Sweden. Waste Manage. (Oxford) 27, 1298-1305 (2007)

Dahlén, L., Vukicevic, S., Tapper, M.: Återvinning av plast från hushållsavfall. Insamlingsresultat och kvalitet av källsorterad plast, Report for Plastkretsen AB, Luleå and Helsingborg (2013)

Dijkgraaf, E., Gradus, R.H.J.M.: Cost savings in unit-based pricing of household waste: the case of Netherlands. Resour. Energy Econ. 26, 353-371 (2004)

Duggal, V.G., Saltzman, C., Williams, M.L.: Recycling: an economic analysis. East. Econ. J. 17(3), 351-358 (1991)

European Commission. Closing the Loop_An EU action plan for the circular economy. COM (2015) 614 final, Brussels, (2015)

European Environment Agency (EEA). Circular Economy in Europe. Developing the Knowledge Base. EEA Report No. 2/2016. Luxembourg, (2016)

Ferrara, I., Missios, P.: Recycling and waste diversion effectiveness: evidence from Canada. Environ. Resour. Econ. 30, 221-238 (2005)

Florax, R.J.G.M., Folmer, H., Rey, S.J.: Specification searches in spatial econometrics: the relevance of Hendry's econometric methodology. Reg. Sci. Urban Econ. 33, 557-579 (2003)

Freedman, D., Peters, S.: Bootstrapping a regression equation: some empirical results. J. Am. Stat. Assoc. 79, 97-106 (1984a)

Freedman, D., Peters, S.: Bootstrapping an econometric model: some empirical results. J. Bus. Econ. Stat. 2, 150-58 (1984b)

Fullerton, D., Kinnaman, T.C.: Household response to pricing garbage by the bag. Am. Econ. Rev. 86(4), 971-984 (1996)

Funck, H.: Återvinningsstationer (Drop-off stations). 2006, March 21. Excel-file. Stockholm, Förpackningsoch tidningsinsamlingen $\mathrm{AB}$ (2006)

Gaeta, L.G., Ghinoi, S., Silvestri, F.: Municipal Performance in Waste Recycling: An Empirical Analysis Based on Data from the Lombardy Region (Italy). Letters in Spatial Resource Sciences 10(3), 337-352 (2017)

Geary, R.: The contiguity ratio and statistical mapping. Inc. Stat. 5, 115-145 (1954)

Getis, A., Ord, J.K.: The analysis of spatial association by use of distance statistics. Geogr. Anal. 24, 189-206 (1992)

Hage, O.: The Swedish producer responsibility for paper packaging: an effective waste management policy? Resour. Conserv. Recycl. 51, 314-344 (2007)

Hage, O., Söderholm, P.: An econometric analysis of regional differences in household waste collection: the case of plastic packaging waste in Sweden. Waste Manage. (Oxford) 28(10), 1720-1731 (2008)

Hage, O., Söderholm, P., Berglund, C.: Norms and economic motivation in household recycling: empirical evidence from Sweden. Resour. Conserv. Recycl. 53(3), 155-165 (2009)

Hornik, J., Cherian, J., Madansky, M., Narayana, C.: Determinants of recycling behavior: a synthesis of research results. J. Soc. Econ. 24(1), 105-127 (1995)

Jenkins, R.R., Martinez, S.A., Palmer, K., Podolsky, M.J.: The determinants of household recycling: a material-specific analysis of recycling program features and unit pricing. J. Environ. Econ. Manag. 45, 294-318 (2003)

Kelejian, H., Robinson, D.: A Suggested method of estimation for spatial inter-dependent models with autocorrelated errors, and an application to a county expenditure model. Paper presented and the $39^{\text {th }}$ North American Meetings of the Regional Science Association, Chicago, IL, November 12-15 (1992)

KFAKTA.: Kommundatabasen KFAKTA06. University of Lund, Department of Political Science, Lund (2006)

Kipperberg, G.: A comparison of household recycling behaviors in Norway and the United States. Environ. Resour. Econ. 26(2), 215-235 (2006)

Kinnaman, T.C.: Policy watch: examining the justification for residential recycling. J. Econ. Perspect. 20(4), 219-232 (2006) 
Kinnaman, T.C., Fullerton, D.: Garbage and recycling with endogenous local policy. J. Urban Econ. 48, 419-442 (2000)

LeSage, J.P.: Spatial Economics Using Matlab. University of Toledo, Toledo (1999)

Li, S.: Recycling behavior under China's social and economic transition. The case of metropolitan Wuhan. Environ. Behav. 35(6), 784-801 (2003)

Lyas, J.K., Shaw, P.J., van Vugt, M.: Kerbside recycling in the London borough of havering: progress and priorities. Resour. Conserv. Recycl. 45, 1-17 (2005)

Mattsson, C., Berg, P., Clarkson, P.: The development of systems for property close collection of recyclables: experiences from Sweden and England. Resour. Conserv. Recycl. 38, 39-57 (2003)

Mattson, O.: Fastighetsnära insamling RVF 2006-09-Conscia. Conscia AB, Löddeköpinge, Sweden (2006)

Mazzanti, M., Montini, A., Nicolli, F.: The dynamics of landfill diversion: economic drivers, policy factors and spatial issues. Evidence from Italy using provincial panel data. Resour. Conserv. Recycl. 54, 53-61 (2009)

Mazzanti, M., Montini, A., Nicolli, F.: Embedding landfill diversion in economic. Geogr. Policy Settings Appl. Econ. 43(24), 3299-3311 (2011)

Moran, P.: The interpretation on statistical maps. J. R. Stat. Soc. B 10, 243-251 (1948)

Nakano, M., Managi, S.: Waste generations and efficiency measures in Japan. Environ. Econ. Policy Stud. 14(4), 327-339 (2012)

National Labour Market Board (AMS). Labor Market Statistics for 2005, Stockholm (2006)

Ord, J.K., Getis, A.: Local spatial autocorrelation statistics: distributional issues and an application. Geogr. Anal. 27(4), 286-306 (1995)

Ord, J.K., Getis, A.: Testing for local spatial autocorrelation in the presence of global autocorrelation. J. Reg. Sci. 41(3), 411-432 (2001)

PAB (2007). Plastkretsen 2007, Stockholm

SCB (2002). Allmänna valen 2002. Sveriges officiella statistik, Statistiska meddelanden, ME 10 SM 0201. Statistics Sweden, Stockholm (2002)

SCB (2005a). Årsbok för Sverige kommuner 2005. Statistics Sweden, Örebro

SCB (2005b). Bostäder 2005. Statistikdatabasen, Statistics Sweden, Stockholm

Schultz, P.W., Oskamp, S., Mainieri, T.: Who recycles and when? A review of personal and situational factors. J. Environ. Psychol. 15, 105-121 (1995)

Sidique, S.F., Joshi, S.V., Lupi, F.: Factors influencing the rate of recycling: an analysis of Minnesota counties. Resour. Conserv. Recycl. 54, 212-249 (2010)

Söderholm, P. (ed.): Environmental Policy and Household Behavior. Sustainability in Everyday Life, Earthscan, London (2010)

Staaf, L.: Insamlingsstatistik för 2005 på kommunnivå (Household Plastic Collection in 2005). Förpacknings- och tidningsinsamlingen AB, Stockholm (2006)

Sterner, T., Bartelings, H.: Household waste management in a Swedish munici-pality: determinants of waste disposal, recycling and composting. Environ. Resour. Econ. 13(13), 473-491 (1999)

Swedish Environmental Protection Agency (SEPA).: A Strategy for Sustainable Waste Management. Sweden's Waste Plan, Stockholm (2005)

Swedish Environmental Protection Agency (SEPA).: Framtida producentansvar för förpackningar och tidningar. Utvärdering av producentansvaret för förpackningar och tidningar samt förslag till åtgärder. Report 5648, Stockholm (2006)

Swedish Road Administration (SRA).: Vägavstånd i Sverige 99. Borlänge (1999)

Thogersen, J.: Recycling and morality. A critical review of the literature. Environ. Behav. 28(4), 536-558 (1996)

Thogersen, J.: Monetary incentives and recycling: behavioural and psychological reactions to a performancedependent garbage fee. J. Consum. Policy 26, 197-228 (2003)

Thomas, C.: Public understanding and its effect on recycling performance in Hampshire and Milton Keynes. Resour. Conserv. Recycl. 32, 259-274 (2001)

Tonglet, M., Phillips, P.S., Read, A.D.: Using the theory of planned behaviour to investigate the determinants of recycling behaviour: a case study from Brixworth, UK. Resour. Conserv. Recycl. 41, 191-214 (2004)

Van Beukering, P.J.H., Bouman, M.A.: Empirical evidence on recycling and trade of paper and lead in developed and developing countries. World Dev. 29(10), 1717-1739 (2001)

Villaägarna.: Sveriges soptaxor 2005 och 2006 (Swedish waste handling fees in 2005 and 2006), Stockholm (2006) 